\title{
Morphological Evolution during Isothermal Crystallization Observed in a Crystalline-Crystalline Diblock Copolymer
}

\author{
By Takuya SAKURAI, Yuya OHGUMA, and Shuichi NOJIMA*
}

\begin{abstract}
Morphological evolution during isothermal crystallization over a long time $(\sim 3 \mathrm{~d})$ in a crystalline-crystalline diblock copolymer, poly( $\varepsilon$-caprolactone)-block-polyethylene (PCL- $b$-PE), has been investigated at various temperatures $T_{\mathrm{c}}$ by SAXS, DSC, and FT/IR techniques. The crystallization temperature of PE blocks was sufficiently higher than that of PCL blocks, so that PE blocks crystallized first by quenching PCL- $b$-PE from a microphase-separated melt into $T_{\mathrm{c}}$ followed by the crystallization of PCL blocks, and eventually PCL+PE-crystallized morphology was formed in the system. The long period $L$, an alternating distance of the morphology, did not change at all during isothermal crystallization after an initial increase in $L$ by the crystallization of both blocks, indicating no apparent change in the morphology at the late stage crystallization. However, DSC and FT/IR results revealed that the crystallinity of PCL blocks significantly increased and simultaneously that of PE blocks decreased moderately with increasing crystallization time at the late stage. These results suggest the partial melting of PE crystals facilitated by further crystallization of PCL blocks in order to compensate the space previously occupied by amorphous PCL blocks.

KEY WORDS: Crystalline-crystalline Diblock Copolymer / Isothermal Crystallization / Morphological Evolution /
\end{abstract}

Crystalline-crystalline diblock copolymers show an interesting morphology formation by the interplay between two kinds of crystallization starting from the microdomain structure formed in the melt. ${ }^{1}$ There are many studies on the crystallization behavior and resulting morphology of double crystalline diblock copolymers, such as poly( $\varepsilon$-caprolactone)-blockpoly(ethylene oxide) (PCL- $b$-PEO), ${ }^{2-11}$ poly( $p$-dioxanone)block-PCL (PPDX-b-PCL), ${ }^{12-14}$ polyethylene-block-PEO (PE$b$-PEO), ${ }^{15-17}$ poly(L-lactide)-block-PCL (PLLA-b-PCL), ${ }^{18-22}$ and PCL- $b$-PE. ${ }^{23-27}$ In PCL- $b$-PEO, both blocks have a close melting temperature $T_{\mathrm{m}}$ and eventually two kinds of crystallization occur simultaneously to result in a characteristic morphology in the system. In other block copolymers, $T_{\mathrm{m}}$ of one block is enough higher than that of the other, and consequently the higher- $T_{\mathrm{m}}$ blocks crystallize first by quenching the copolymer from a microphase-separated melt into low temperatures, followed by the crystallization of lower- $T_{\mathrm{m}}$ blocks starting from the crystallized solid morphology already formed in the system. In dynamic studies on the morphology formation in such systems, the early stage crystallization of higher- $T_{\mathrm{m}}$ blocks and/or lower- $T_{\mathrm{m}}$ blocks was mainly investigated by time-resolved small-angle X-ray scattering with synchrotron radiation (SR-SAXS), where the SAXS curves show a drastic change by the crystallization of each block.

We have recently investigated the melting behavior of PCL$b$-PE diblocks by SR-SAXS, and found that the long period $L$, an alternating distance of the morphology, changed complicatedly during heating. ${ }^{26}$ In particular, $L$ decreased discontinuously at $T_{\mathrm{m}}$ of PCL blocks (lower- $T_{\mathrm{m}}$ blocks) for all PCL- $b$ PE copolymers investigated. We speculated that this decrease in $L$ might arise from further morphological evolution at $T_{\mathrm{c}}$ over a long time after the early stage crystallization observed by SR-SAXS. However, this morphological change cannot be pursued by SR-SAXS, and therefore we have to use conventional techniques to observe it.

In this study, we investigate the morphological evolution occurring in PCL- $b$-PE during isothermal crystallization over $3 \mathrm{~d}$ by using SR-SAXS, conventional SAXS (C-SAXS), differential scanning calorimetry (DSC), and Fourier transform infrared spectroscopy (FT/IR) techniques. We analyze the local change as well as the total change in morphology at the late stage crystallization. We finally try to explain the characteristic melting behavior previously observed in PCL$b$-PE on the basis of morphological evolution found in this study.

\section{EXPERIMENTAL}

\section{Samples}

The PCL- $b$-PE copolymer was obtained by the hydrogenation of a PCL-block-polybutadiene (PCL- $b$-PB) copolymer anionically synthesized. The methods of PCL- $b$-PB synthesis and the hydrogenation were already described elsewhere. ${ }^{28,29}$ Molecular characteristics of PCL- $b$-PE, together with those of PCL and PE homopolymers, are shown in Table I, where the total number-averaged molecular weight $M_{\mathrm{n}}$ is 13,000 , which means the microdomain structure is not stable against the crystallization of PE blocks yielding a morphological transformation from a microdomain structure into a solid lamellar morphology (break-out crystallization). ${ }^{23}$ The PCL and PE homopolymers were commercial products. 
Table I. Samples used in this study

\begin{tabular}{|c|c|c|c|c|c|c|}
\hline sample code & total $M_{\mathrm{n}}{ }^{\mathrm{a})}$ & $M_{\mathrm{w}} / M_{\mathrm{n}}^{\mathrm{b})}$ & $\begin{array}{c}\text { PCL:PEc) } \\
\text { (vol. \%) }\end{array}$ & $\begin{array}{c}\text { PCL:PEc) } \\
\text { (wt. \%) }\end{array}$ & $\begin{array}{c}T_{m, P C L}{ }^{\mathrm{d})} \\
\left({ }^{\circ} \mathrm{C}\right)\end{array}$ & $\begin{array}{c}T_{m, P E}{ }^{\mathrm{d})} \\
\left({ }^{\circ} \mathrm{C}\right)\end{array}$ \\
\hline E36 & 13,000 & 1.16 & $64: 36$ & 69:31 & 59 & 97 \\
\hline$P E^{e)}$ & 4,700 & 1.05 & $0: 100$ & $0: 100$ & - & 99 \\
\hline$\left.P C L^{e}\right)$ & 11,000 & 1.18 & $100: 0$ & $100: 0$ & 55 & - \\
\hline
\end{tabular}

Differential Scanning Calorimetry (DSC) Measurements

A Perkin Elmer DSC Pyris 1 was used to investigate the melting temperature and the crystallinity of PCL and PE blocks. The samples isothermally crystallized at each crystallization temperature $T_{\mathrm{c}}\left(25^{\circ} \mathrm{C} \leq T_{\mathrm{c}} \leq 45^{\circ} \mathrm{C}\right)$ for selected crystallization times $t_{\mathrm{c}}(\leq 4300 \mathrm{~min})$ were heated at $10^{\circ} \mathrm{C} /$ min, where we observed endothermic peaks due to the melting of both blocks. The crystallinity of PCL and PE blocks, $\chi_{\mathrm{PCL}}\left(t_{\mathrm{c}}\right)$ and $\chi_{\mathrm{PE}}\left(t_{\mathrm{c}}\right)$, was calculated by assuming that the heat of fusion for perfect PCL and PE crystals was $135.4 \mathrm{~J} / \mathrm{g}^{30}$ and $277 \mathrm{~J} / \mathrm{g},{ }^{31}$ respectively.

\section{Synchrotron Small-Angle X-ray Scattering (SR-SAXS) Measurements}

Microphase-separated samples at $120^{\circ} \mathrm{C}$ were quenched into each $T_{\mathrm{c}}\left(25^{\circ} \mathrm{C} \leq T_{\mathrm{c}} \leq 50^{\circ} \mathrm{C}\right)$, and the early stage crystallization $\left(t_{\mathrm{c}}<60 \mathrm{~min}\right)$ was pursued by a time-resolved SR-SAXS method.

The SR-SAXS measurement was performed at Photon Factory in high-energy accelerator research organization, Tsukuba Japan, with a small-angle X-ray equipment for solution installed at beam line BL-10C. Details of the equipment and the intensity correction procedure were already described elsewhere. ${ }^{32-34}$ Accumulation time for each frame was $10 \mathrm{~s}$, and measurements were continued until an integrated intensity did not practically change any more. The SAXS curves were finally obtained as a function of $s=(2 / \lambda) \sin \theta$, where $\lambda$ is the wavelength of incident X-ray $(=0.1488 \mathrm{~nm})$ and $2 \theta$ the scattering angle. Parameters characterizing the crystallization behavior were finally extracted from these SAXS curves as a function of $t_{\mathrm{c}}$. In this study, we focus our attention on the $t_{\mathrm{c}}$ dependence of long period $L$.

\section{Conventional Small-Angle X-ray Scattering (C-SAXS) Measurements}

C-SAXS measurements were performed by using a Rigaku Nano-Viewer with a rotating-anode X-ray generator operating at $45 \mathrm{kV}$ and $60 \mathrm{~mA}$ to pursue the late stage crystallization (60 $\mathrm{min} \leq t_{\mathrm{c}} \leq 4300 \mathrm{~min}$ ), where the sample was isothermally crystallized at each $T_{\mathrm{c}}$. The detector was a one-dimensional position-sensitive proportional counter (PSPC), and the accumulation time for each measurement was $1 \mathrm{~h}$. Methods of data treatment were the same to those of SR-SAXS measurements. Here, we also evaluated the $t_{\mathrm{c}}$ dependence of $L$, and eventually we could obtain the change in $L$ over a whole crystallization process $\left(0 \mathrm{~min}<t_{\mathrm{c}} \leq 4300 \mathrm{~min}\right)$ by the combined methods of SR-SAXS and C-SAXS.

\section{Fourier Transform Infrared Spectroscopy (FT/IR) Meas- urements}

FT/IR spectra were recorded during isothermal crystallization $\left(t_{\mathrm{c}} \leq 4300 \mathrm{~min}\right)$ at selected $T_{\mathrm{c}}$ ranging from $25^{\circ} \mathrm{C}$ to $53^{\circ} \mathrm{C}$ using JASCO FT/IR6200 spectrometer with a spectral resolution of $4 \mathrm{~cm}^{-1}$, and the time evolution of relative crystallinity for PCL and PE blocks, $\chi_{\mathrm{PCL}}^{\prime}\left(t_{\mathrm{c}}\right)$ and $\chi_{\mathrm{PE}}^{\prime}\left(t_{\mathrm{c}}\right)$, was evaluated. The sample was first dissolved in toluene and thin films ( $c a$. $100 \mu \mathrm{m}$ in thickness) were prepared by the solution-casting method on a silicone plate. The absorption bands at $731 \mathrm{~cm}^{-1}$ for PCL and PE blocks and at $960 \mathrm{~cm}^{-1}$ for PCL blocks were mainly analyzed to evaluate the change in $\chi_{\mathrm{PCL}}^{\prime}\left(t_{\mathrm{c}}\right)$ and $\chi_{\mathrm{PE}}^{\prime}\left(t_{\mathrm{c}}\right)$ with increasing $t_{\mathrm{c}}$. That is, the band at $960 \mathrm{~cm}^{-1}$ arises from C-O-C symmetric stretching in PCL crystals ${ }^{35}$ and that at $731 \mathrm{~cm}^{-1}$ from a combination of $\mathrm{CH}_{2}$ rocking motion in PCL and PE crystals, ${ }^{35,36}$ so that we first evaluated $\chi_{\text {PCL }}^{\prime}\left(t_{\mathrm{c}}\right)$ from the $960 \mathrm{~cm}^{-1}$ band at each $t_{\mathrm{c}}$, and then $\chi_{\mathrm{PE}}^{\prime}\left(t_{\mathrm{c}}\right)$ from the $731 \mathrm{~cm}^{-1}$ band by subtracting $\chi_{\text {PCL }}^{\prime}\left(t_{\mathrm{c}}\right)$. The tail of $\mathrm{CH}_{2}$ rocking motion of amorphous components, which is centered at $720 \mathrm{~cm}^{-1}$, is included in the intensity at $731 \mathrm{~cm}^{-1}, 36$ but this amount is very small and eventually does not give the significant influence on the experimental results obtained.

\section{RESULTS}

\section{Long Period Measured by SAXS}

Figure 1a shows typical SR-SAXS curves during early stage crystallization $\left(t_{\mathrm{c}}<40 \mathrm{~min}\right)$ for E36 when it is quenched from $120^{\circ} \mathrm{C}$ (microphase-separated melt) into $40^{\circ} \mathrm{C}$. We can observe a sharp diffraction and a small second-order peak arising from the microdomain structure just after quenching, which turn quickly into a small scattering peak with a considerable shift of the peak position, indicating that the microdomain structure is completely transformed into the lamellar morphology by the crystallization of PE blocks (PE lamellar morphology). This PE lamellar morphology is not regular compared to the microdomain structure, so that the intensity peak is diffuse without any higher-order peaks. After some induction time, the peak intensity increases gradually with increasing $t_{\mathrm{c}}$, which suggests that PCL blocks start to crystallize from the existing PE lamellar morphology. The late stage crystallization $\left(t_{\mathrm{c}}>60 \mathrm{~min}\right)$ was pursued by C-SAXS. Figure $1 \mathrm{~b}$ shows C-SAXS curves at selected $t_{\mathrm{c}}$ indicated, where the peak intensity and peak position remain almost constant irrespective of $t_{\mathrm{c}}$. These facts suggest that C-SAXS methods cannot detect any substantial change in the morphology at the late stage crystallization.

The long period of lamellar morphology $L$ for E36, obtained from Lorentz-corrected SR-SAXS and C-SAXS curves, was plotted in Figure 2 against $t_{\mathrm{c}}$ for selected $T_{\mathrm{c}}$, where open symbols were obtained by SR-SAXS and closed symbols by C-SAXS. The value of $L$ increases suddenly at the beginning of crystallization $\left(t_{\mathrm{c}}<0.2 \mathrm{~min}\right)$ and after that it shows a two-step 

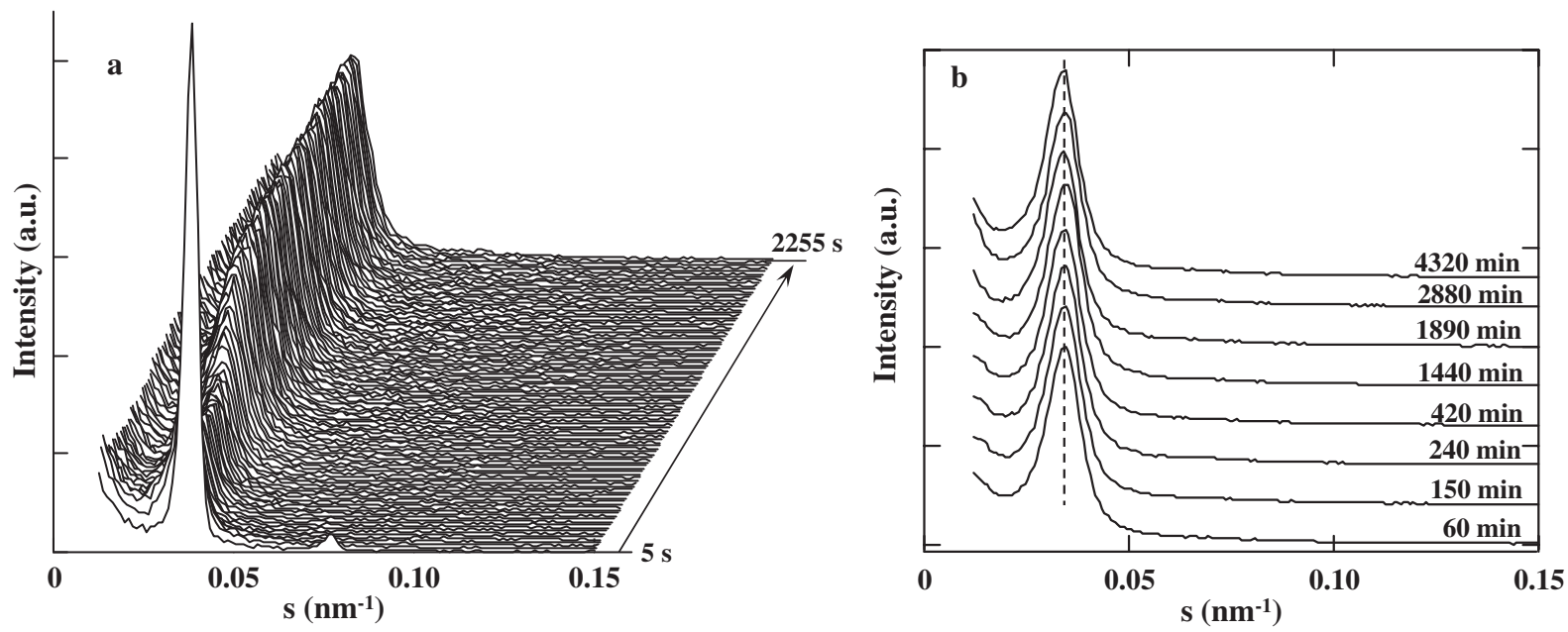

Figure 1. (a) Time-resolved SR-SAXS curves when E36 is quenched from the microphase-separated melt into $T_{\mathrm{c}}=40^{\circ} \mathrm{C}$. The accumulation time for each measurement is $10 \mathrm{~s}$. (b) C-SAXS curves at selected crystallization times for E36 crystallized at $T_{\mathrm{c}}=40^{\circ} \mathrm{C}$. The accumulation time for each measurement is $60 \mathrm{~min}$, and the crystallization time represents the middle time during measurement.

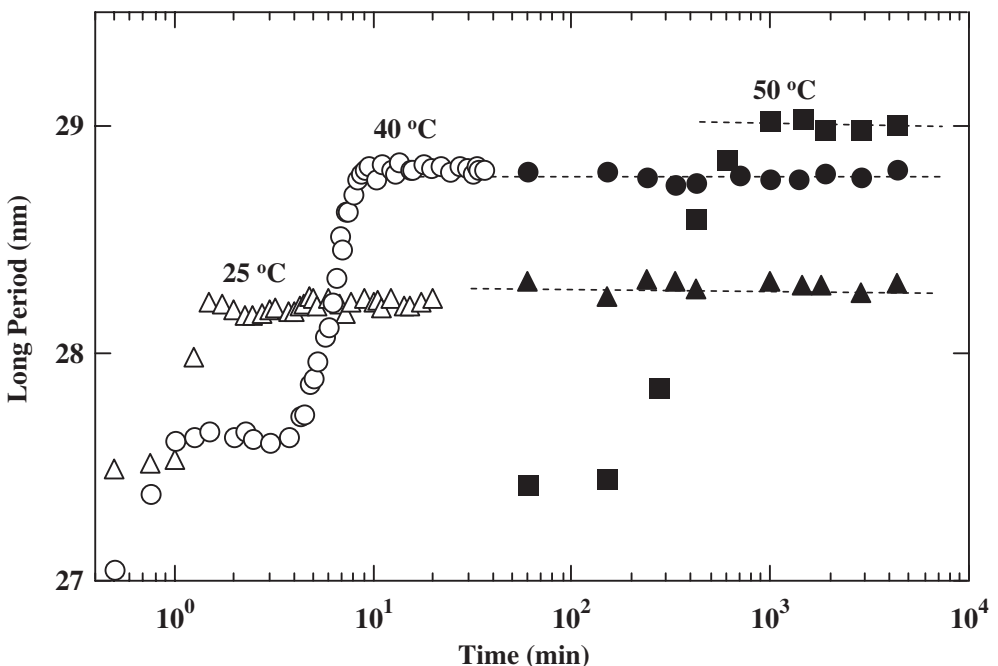

Figure 2. Long period, evaluated from the Lorentz-corrected SAXS curves, plotted against crystallization time for $\mathrm{E} 36 \mathrm{crystallized} \mathrm{at} 25^{\circ} \mathrm{C}(\triangle, \boldsymbol{\Delta}), 40^{\circ} \mathrm{C}(\bigcirc, \bigcirc)$ and $50^{\circ} \mathrm{C}(\square, \square)$. The open symbols represent SR-SAXS results and closed symbols C-SAXS results.

increase at the initial stage (see, for example, data at $40^{\circ} \mathrm{C}$ ), and they connect consistently with $L$ obtained by C-SAXS. In addition, the final $L$ increases smoothly with increasing $T_{\mathrm{c}}$, as shown in Figure 3; at lower $T_{\mathrm{c}}\left(<35^{\circ} \mathrm{C}\right) L$ is almost constant while it increases moderately with increasing $T_{\mathrm{c}}$. We previously reported the $T_{\mathrm{c}}$ dependence of $L$ and explained it by the difference in crystallization mechanism between higher $T_{\mathrm{c}}$ and lower $T_{\mathrm{c}} ;^{23,24}$ at lower $T_{\mathrm{c}}$ PCL blocks crystallize within the existing PE lamella morphology while at higher $T_{\mathrm{c}}$ they crystallize by destroying or deforming the existing PE lamellar morphology to form a new lamellar morphology favorable for the crystallization for PCL blocks (PCL lamellar morphology).

Figures 2 and 3 show that $L$ at the late stage crystallization does not depend on $t_{\mathrm{c}}$ but significantly depends on $T_{\mathrm{c}}$. Figure 2 is quite different from the crystallization behavior usually observed in homopolymers, that is, $L$ increases steadily with increasing $t_{\mathrm{c}}$ for homopolymer crystallization. ${ }^{37,38}$ This fact is

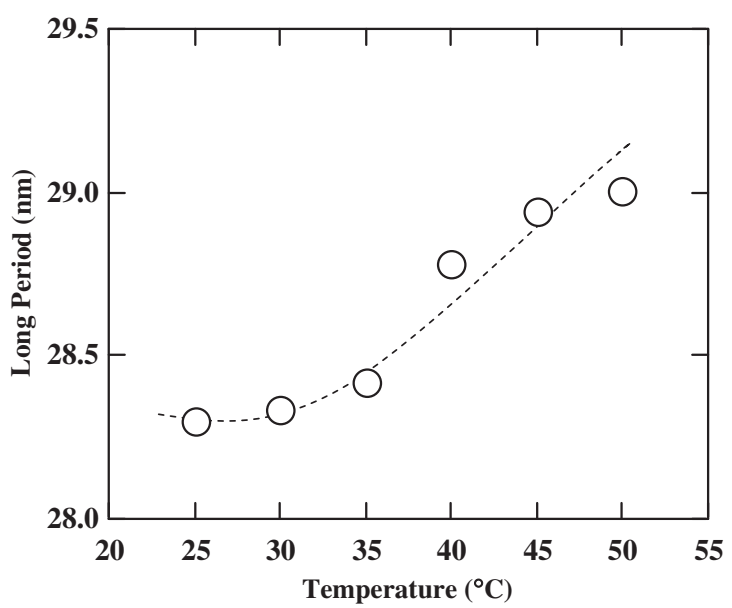

Figure 3. Long period after isothermal crystallization for $4300 \mathrm{~min}$ plotted against crystallization temperature for E36. 

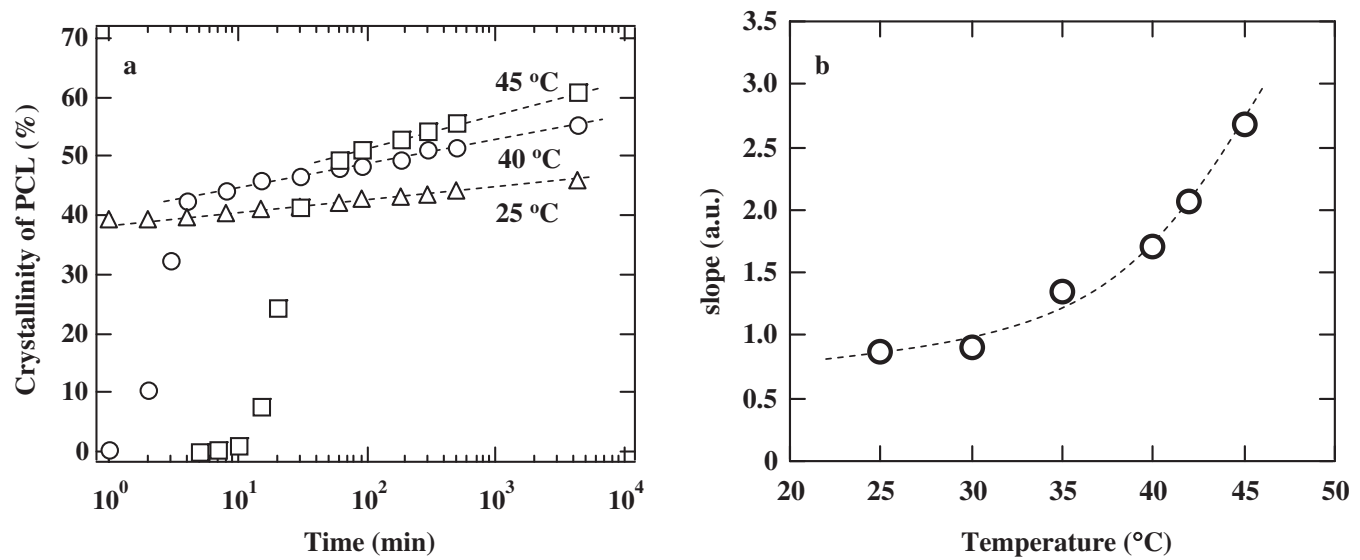

Figure 4. (a) The crystallinity of PCL blocks obtained by DSC plotted against crystallization time for $\mathrm{E} 36$ crystallized at $25^{\circ} \mathrm{C}(\triangle), 40^{\circ} \mathrm{C}(\bigcirc)$, and $45^{\circ} \mathrm{C}(\square)$. (b) The slope in Figure 4a at the late stage crystallization plotted against crystallization temperature.

explained by lamella thickening (or decrease in fold number), and eventually the crystallinity increases gradually with increasing $t_{\mathrm{c}}$. Therefore, the lamellar morphology formed in PCL- $b$-PE seems to be substantially different from that formed in usual crystalline homopolymers from the viewpoint of the $t_{\mathrm{c}}$ dependence of $L$ at the late stage crystallization.

\section{Crystallinity Measured by DSC}

DSC methods were employed to obtain the crystallinity of PCL blocks $\chi_{\mathrm{PCL}}\left(t_{\mathrm{c}}\right)$, which is plotted in Figure $4 \mathrm{a}$ as a function of $t_{\mathrm{c}}$ for selected $T_{\mathrm{c}}$. Note that the endothermic peak for PE melting was considerably small and diffuse compared to that for PCL melting (see, Figure 5 of ref 26), so that it was practically impossible to unambiguously evaluate the $t_{\mathrm{c}}$ dependence of the crystallinity of PE blocks $\chi_{\mathrm{PE}}\left(t_{\mathrm{c}}\right)$. The value of $\chi_{\mathrm{PCL}}\left(t_{\mathrm{c}}\right)$ increases drastically at the early stage crystallization and then increases gradually with increasing $t_{\mathrm{c}}$, as shown in Figure 4a. It is known that the overall crystallinity of crystalline homopolymers at the late stage increases linearly with $\log t_{\mathrm{c}}$, which arises from lamella thickening at this stage. Marand and Huang, for example, investigated the relation between crystallinity evolution and melting temperature for a linear PE fraction, where the PE crystallinity definitely shows a logarithmic increase with $t_{\mathrm{c}}$ at the late stage crystallization. ${ }^{38}$

In order to quantitatively evaluate the gradual increase in $\chi_{\mathrm{PCL}}\left(t_{\mathrm{c}}\right)$ at the late stage crystallization, the slope in Figure $4 \mathrm{a}$ is phenomenologically plotted in Figure $4 \mathrm{~b}$ as a function of $T_{\mathrm{c}}$. We can find positive slopes at every $T_{\mathrm{c}}$ which increase moderately with increasing $T_{\mathrm{c}}$. Figure 4 indicates clearly that PCL blocks crystallize further during the late stage, and moreover the crystallization rate accelerates with increasing $T_{\mathrm{c}}$. The $t_{\mathrm{c}}$ and $T_{\mathrm{c}}$ dependences of $\chi_{\mathrm{PCL}}\left(t_{\mathrm{c}}\right)$ shown in Figure 4 are consistent with the results usually observed in crystalline homopolymers. That is, the crystallization behavior of PCL blocks starting from the pre-existing PE lamellar morphology is similar to that of PCL homopolymers starting from the molten state without any structure.

The DSC results may contain the additional crystallization and/or melting of PCL blocks during heating process, which smear out true morphological change occurring at $T_{\mathrm{c}}$. That is, the higher crystallinity observed might arise from the recrystallization of amorphous PCL blocks during heating from $T_{\mathrm{c}}$ up to $T_{\mathrm{m}, \mathrm{PCL}}$, which is sometimes observed in homopolymer crystallization. In order to find the true change in $\chi_{\mathrm{PCL}}\left(t_{\mathrm{c}}\right)$ during isothermal crystallization at $T_{\mathrm{c}}$, it is necessary to evaluate the time evolution of $\chi_{\mathrm{PCL}}\left(t_{\mathrm{c}}\right)$ (and possibly $\chi_{\mathrm{PE}}\left(t_{\mathrm{c}}\right)$ ) at $T_{\mathrm{c}}$. Wide-angle X-ray diffraction (WAXD) is a suitable method to observe the time evolution of $\chi_{\mathrm{PCL}}\left(t_{\mathrm{c}}\right)$ and $\chi_{\mathrm{PE}}\left(t_{\mathrm{c}}\right)$ separately at $T_{\mathrm{c}}$. However, the diffraction pattern from PE crystals is almost identical with that from PCL crystals, ${ }^{26,39}$ so that it is impossible to evaluate $\chi_{\mathrm{PCL}}\left(t_{\mathrm{c}}\right)$ and $\chi_{\mathrm{PE}}\left(t_{\mathrm{c}}\right)$ separately by WAXD. Therefore we employed FT/IR methods to do it.

\section{Crystallinity Measured by FT/IR}

Figure 5 shows typical FT/IR curves of E36 crystallized at $T_{\mathrm{c}}=40{ }^{\circ} \mathrm{C}$ for $t_{\mathrm{c}}=4300 \mathrm{~min}$. We analyzed the bands appearing at $960 \mathrm{~cm}^{-1}$ and $731 \mathrm{~cm}^{-1}$, the former represented the relative crystallinity of only PCL blocks, while the latter the combined crystallinity of PCL and PE blocks (see, the insets in

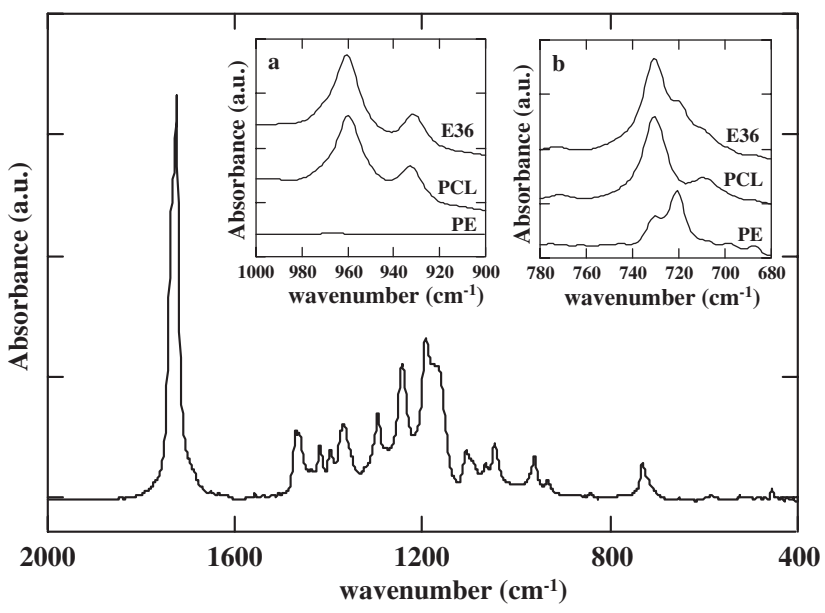

Figure 5. FT/IR curves for $\mathrm{E} 36$ crystallized at $40^{\circ} \mathrm{C}$ for $4300 \mathrm{~min}$. The insets show the detailed FT/IR curves for E36, PCL, and PE at the selected ranges of wave number. 


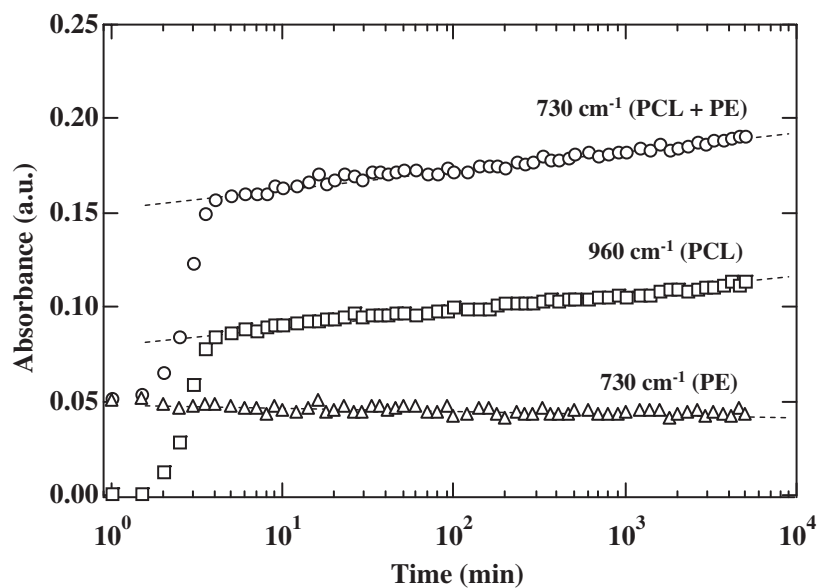

Figure 6. FT/IR absorbance at selected wave numbers plotted against crystallization time for E36 crystallized at $40^{\circ} \mathrm{C}$.

Figure 5). We first evaluated the ratio of the band intensity at $960 \mathrm{~cm}^{-1}$ and $731 \mathrm{~cm}^{-1}$ for a PCL homopolymer and found to be 1.30 , and then separated the $730 \mathrm{~cm}^{-1}$ band into two, one arising from PCL crystals and the other from PE crystals to evaluate $\chi_{\mathrm{PCL}}^{\prime}\left(t_{\mathrm{c}}\right)$ and $\chi_{\mathrm{PE}}^{\prime}\left(t_{\mathrm{c}}\right)$ separately.

The $t_{\mathrm{c}}$ dependence of the $730 \mathrm{~cm}^{-1}$ band (proportional to $\left.\chi_{\mathrm{PCL}}^{\prime}\left(t_{\mathrm{c}}\right)+\chi_{\mathrm{PE}}^{\prime}\left(t_{\mathrm{c}}\right)\right)$, the $960 \mathrm{~cm}^{-1}$ band $\left(\chi_{\mathrm{PCL}}^{\prime}\left(t_{\mathrm{c}}\right)\right)$, and the $730 \mathrm{~cm}^{-1}$ band only arising from PE crystals $\left(\chi_{\mathrm{PE}}^{\prime}\left(t_{\mathrm{c}}\right)\right)$ was shown in Figure 6. The absorbance by PCL crystals increases significantly while that by PE crystals decreases slightly with increasing $t_{\mathrm{c}}$. This fact indicates that PCL blocks crystallize steadily during the late stage crystallization, which is the same result obtained by DSC. The new finding obtained in this study is that PE crystals gradually melt according as further crystallization of PCL blocks, that is, the (PCL) crystallization-induced (PE) melting was observed during the late stage crystallization of PCL- $b$-PE.

This crystallization-induced melting was first reported by Hamley et al. $^{22}$ using a time-resolved WAXD method in a crystalline-crystalline diblock copolymer, poly(L-lactide)block-poly( $\varepsilon$-caprolactone) (PLLA- $b$-PCL), where the primary crystallization of amorphous PCL blocks (lower- $T_{\mathrm{m}}$ blocks) yielded the partial melting of pre-existing PLLA crystals (higher- $T_{\mathrm{m}}$ blocks) just after quenching PLLA- $b$-PCL into low temperatures. They concluded that the melting of PLLA crystals occurred partially in order to compensate the space previously occupied by amorphous PCL blocks. In our system, however, the significant melting of PE blocks could not be detected by FT/IR when PCL blocks started to crystallize. Alternatively, we confirmed the gradual melting of pre-existing PE crystals by further crystallization of amorphous PCL blocks at the late stage. The partial melting of PE crystals seems to have the same origin with the case of PLLA- $b$-PCL, that is, it arises from the compensation of the space previously occupied by amorphous PCL blocks.

In order to quantitatively analyze the change in $\chi_{\mathrm{PCL}}^{\prime}\left(t_{\mathrm{c}}\right)$ and $\chi_{\mathrm{PE}}^{\prime}\left(t_{\mathrm{c}}\right)$ with increasing $t_{\mathrm{c}}$, the slope at late stage crystallization in Figure 6 is plotted in Figure $7 \mathrm{a}$ against $T_{\mathrm{c}}$, where the slope of PCL blocks increases significantly with increasing $T_{\mathrm{c}}$, and this increase nearly corresponds to the negative slope of PE blocks (Figure 7b), suggesting a delicate balance between the partial melting of PE crystals and further crystallization of amorphous PCL blocks. That is, the increasing amount of PCL crystals is roughly proportional to the decreasing amount of PE crystals in the system.

Figure 8 summarizes all experimental results obtained in this study as a function of $T_{\mathrm{c}}$, where we plot the difference in measured values between $t_{\mathrm{c}}=4300 \mathrm{~min}$ and $1000 \mathrm{~min}$ divided by the value at $t_{\mathrm{c}}=1000 \mathrm{~min}$ (i.e., $\frac{A(4300)-A(1000)}{A(1000)}$ with $A=L$, $\chi_{\mathrm{PCL}}, \chi_{\mathrm{PCL}}^{\prime}$ or $\left.\chi_{\mathrm{PE}}^{\prime}\right)$. By taking these reduced values, which are roughly correspond to the slopes we have previously introduced in Figures $4 \mathrm{~b}$ and $7 \mathrm{a}$, it is possible to directly compare the different sets of experimental results obtained by SAXS, DSC, and FT/IR.

The difference in $L$ is almost zero irrespective of $T_{\mathrm{c}}$, indicating that the macroscopic change in morphology cannot be detected by SAXS, and the total morphology seems to be unchanged during the late stage crystallization. The difference in $\chi_{\mathrm{PCL}}$ measured by DSC takes positive values, indicating the PCL crystallinity increases significantly during the late stage crystallization. This increase in $\chi_{\mathrm{PCL}}$ accelerates at higher $T_{\mathrm{c}}$. In addition, the $T_{\mathrm{c}}$ dependence of $\chi_{\mathrm{PCL}}$ obtained by DSC is completely consistent with that obtained by FT/IR, as shown in Figure 8 . However, the difference in $\chi_{\mathrm{PE}}^{\prime}$ obtained by FT/IR
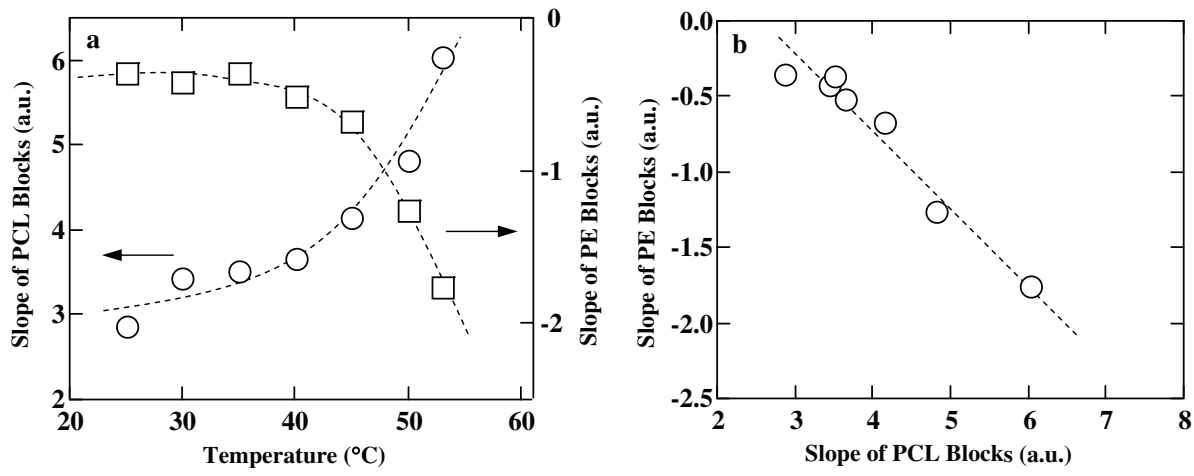

Figure 7. (a) The slope in Figure 6 at the late stage crystallization plotted against crystallization temperature for PCL blocks ( $\bigcirc$ ) and PE blocks ( $\square$ ). (b) The slope for PE blocks plotted against the slope for PCL blocks. 


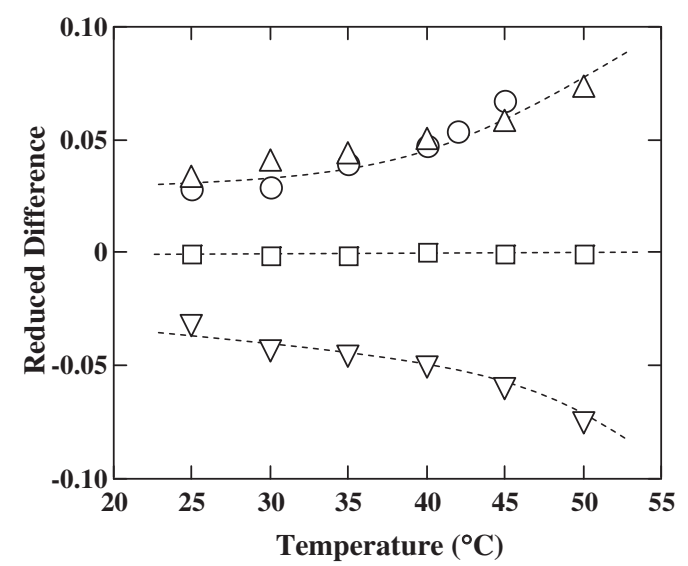

Figure 8. Difference in measured values between $t_{\mathrm{c}}=4300 \mathrm{~min}$ and $1000 \mathrm{~min}$ divided by the value at $t_{\mathrm{C}}=1000 \mathrm{~min}, \frac{A(4300)-A(1000)}{A(1000)}$ with $A=L, \chi_{\mathrm{PCL}}, \chi_{\mathrm{PCL}}^{\prime}$ or $\chi_{\mathrm{PE}}^{\prime}$, plotted against crystallization temperature. $\square$ : Long period obtained by C-SAXS. $\bigcirc$ : PCL crystallinity obtained by DSC. $\triangle$ : PCL crystallinity obtained by FT/IR. $\nabla: \mathrm{PE}$ crystallinity obtained by FT/IR.

takes negative values, indicating the crystallinity of PE blocks decreases during the late stage crystallization. In addition, this decrease accelerates with increasing $T_{\mathrm{c}}$, which forms a remarkable contrast with the increase in PCL crystallinity. From above results we can conclude that the local structure of the lamellar morphology changes appreciably during the late stage crystallization. This change will be determined by a delicate balance between the driving force of PCL crystallization and the stability of PE crystals against melting. Therefore, many factors, such as $T_{\mathrm{c}}$, molecular weight of each block, and crystallinity of PE blocks (or ethyl branch content) will totally affect the result shown in Figure 8.

\section{DISCUSSION}

\section{Volume Change by Simultaneous Crystallization and Melting}

Here, we consider the amount of volume change by simultaneous crystallization and melting at the late stage crystallization $\left(1000 \mathrm{~min} \leq t_{\mathrm{c}} \leq 4300 \mathrm{~min}\right)$. The volume change per $1 \mathrm{~g}$ PCL- $b$-PE consists of the volume decrease by further crystallization of PCL blocks $\Delta v_{\mathrm{PCL}}$ and the volume increase by the melting of PE blocks $\Delta v_{\mathrm{PE}}$, which can be written as,

$$
\begin{aligned}
& \Delta v_{\mathrm{PCL}}\left(T_{\mathrm{c}}\right)=\chi_{\mathrm{PCL}}(1000) \Delta \chi_{\mathrm{PCL}} \phi_{\mathrm{w}, \mathrm{PCL}}\left(v_{\mathrm{c}, \mathrm{PCL}}-v_{\mathrm{a}, \mathrm{PCL}}\right) \\
& \Delta v_{\mathrm{PE}}\left(T_{\mathrm{c}}\right)=\chi_{\mathrm{PE}}(1000) \Delta \chi_{\mathrm{PE}}\left(1-\phi_{\mathrm{w}, \mathrm{PCL}}\right)\left(v_{\mathrm{c}, \mathrm{PE}}-v_{\mathrm{a}, \mathrm{PE}}\right)
\end{aligned}
$$

where $\chi_{\mathrm{X}}(1000)(\mathrm{X}=\mathrm{PCL}$ or PE) is the crystallinity of $1 \mathrm{~g}$ PCL or PE blocks at $t_{\mathrm{c}}=1000$ min obtained by DSC, $\Delta \chi_{\mathrm{X}}$ is the reduced difference in crystallinity between $t_{\mathrm{c}}=1000 \mathrm{~min}$ and $4300 \mathrm{~min}$ obtained by FT/IR (Figure 8), $\phi_{\mathrm{w}, \mathrm{PCL}}$ is the weight fraction of PCL blocks in the system (Table I), and $v_{\mathrm{c}, \mathrm{X}}$ and $v_{\mathrm{a}, \mathrm{X}}$ are the specific volume of crystallized and amorphous blocks, respectively. For PCL and PE crystals we used $v_{\mathrm{c}, \mathrm{PCL}}=0.833\left(\mathrm{~cm}^{3} / \mathrm{g}\right)^{39}$ and $v_{\mathrm{c}, \mathrm{PE}}=1.000\left(\mathrm{~cm}^{3} / \mathrm{g}\right),{ }^{40}$ respectively, irrespective of $T_{\mathrm{c}}$, and for the amorphous $\mathrm{PCL}^{30}$

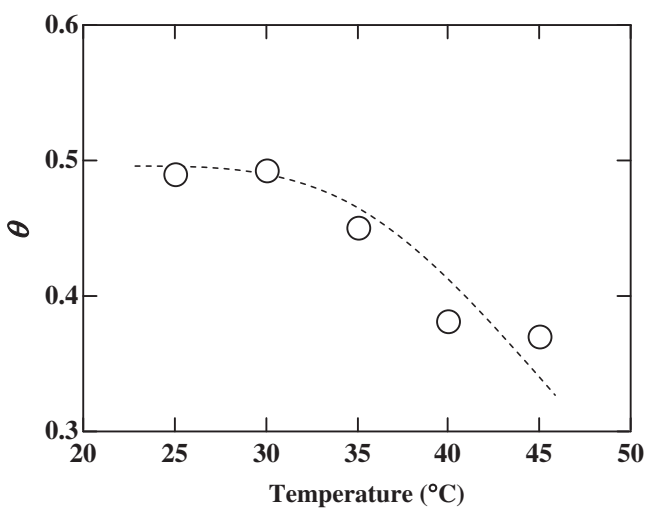

Figure 9. $\theta$ plotted against crystallization temperature for E36.

$$
v_{\mathrm{a}, \mathrm{PCL}}=0.9106+\left(6.01 \times 10^{-4}\right) T_{\mathrm{c}}
$$

and for the amorphous $\mathrm{PE}^{41}$

$$
v_{\mathrm{a}, \mathrm{PE}}=1.1696+\left(1.77 \times 10^{-4}\right) T_{\mathrm{c}}
$$

where $v_{\mathrm{a}, \mathrm{PCL}}$ and $v_{\mathrm{a}, \mathrm{PE}}$ are in $\mathrm{cm}^{3} / \mathrm{g}$ and $T_{\mathrm{c}}$ is in ${ }^{\circ} \mathrm{C}$.

Next, we introduce the parameter $\theta\left(T_{\mathrm{c}}\right)$ defined by,

$$
\theta\left(T_{\mathrm{c}}\right)=-\frac{\Delta v_{\mathrm{PE}}\left(T_{\mathrm{c}}\right)}{\Delta v_{\mathrm{PCL}}\left(T_{\mathrm{c}}\right)}
$$

$\theta\left(T_{\mathrm{c}}\right)$ represents the ratio of volume increase by the melting of PE crystals against volume decrease by the crystallization of amorphous PCL blocks between $t_{\mathrm{c}}=1000 \mathrm{~min}$ and $4300 \mathrm{~min}$. Therefore $\theta\left(T_{\mathrm{c}}\right)$ should be unity when the volume changes of both blocks are just the same, and it takes the value between 0 and 1 when the volume change of crystallized PCL blocks is larger than that of melted PE blocks.

Figure 9 shows the $T_{\mathrm{c}}$ dependence of $\theta\left(T_{\mathrm{c}}\right)$, where $\theta\left(T_{\mathrm{c}}\right)$ is equal to or less than 0.5 at every $T_{\mathrm{c}}$ investigated, indicating that the volume decrease by the crystallization of PCL blocks is much larger than the volume increase by the melting of PE crystals. In addition, we can find that $\theta\left(T_{\mathrm{c}}\right)$ decreases significantly with increasing $T_{\mathrm{c}}$, which mainly arises from the difference in final crystallinity between PCL and PE blocks at $T_{\mathrm{c}} ; \chi_{\mathrm{PCL}}(4300)$ increases steadily with increasing $T_{\mathrm{c}}$ (Figure 4a) while $\chi_{\mathrm{PE}}(4300)$ is almost constant $(\sim 27 \%)$ irrespective of $T_{\mathrm{c}}$. That is, Figure 9 shows that the melting of PE crystals facilitated by the crystallization of PCL blocks cannot completely compensate the space previously occupied by the amorphous PCL blocks, and eventually the density of amorphous PCL and/or PE blocks is expected to be smaller than that of amorphous PCL and/or PE homopolymers because the size of total lamellar morphology (or long period) does not change at all during the late stage crystallization (Figure 8). The density of amorphous blocks in the lamellar morphology further decreases with increasing $T_{\mathrm{c}}$ because the larger amount of amorphous PCL blocks crystallizes at higher $T_{\mathrm{c}}$ compared to the melted amount of PE crystals. This unbalanced change in volume may be responsible for the characteristic melting behavior previously observed in PCL- $b$ $\mathrm{PE}^{26}$ 


\section{Effects of Local Change in Morphology on the Melting Behavior of PCL- $b$-PE}

In our recent study, ${ }^{26}$ we reported that $L$ decreased discontinuously at the melting temperature of PCL blocks $\left(T_{\mathrm{m}, \mathrm{PCL}}\right)$ during heating process at a constant rate. This decrease in $L$ could be observed for all PCL- $b$-PE copolymers crystallized at every $T_{\mathrm{c}}$ investigated. Therefore it is expected to be a general phenomenon observed in the heating process of crystalline-crystalline diblock copolymers. We found in this study that PCL blocks crystallized further and simultaneously PE crystals melted partially during isothermal crystallization at $T_{\mathrm{c}}\left(<T_{\mathrm{m}, \mathrm{PCL}}\right)$ with $L$ being unchanged. We qualitatively discuss here the relationship between the morphological evolution during isothermal crystallization at $T_{\mathrm{c}}$ and the discontinuous decrease in $L$ observed at $T_{\mathrm{m}, \mathrm{PCL}}$ during subsequent heating process.

If we assume that the partial melting of PE crystals yields the lamella thinning of PE crystals, PE lamellae just after the melting of PCL crystals are thinner than those just before the crystallization of PCL blocks on quenching into $T_{\mathrm{c}}$. This assumption is based on the experimental facts observed in crystalline homopolymers, where the increase (or decrease) in crystallinity corresponds to lamella thickening (or thinning), though we did not detect any significant decrease in the melting temperature of PE crystals by DSC. This might be ascribed to the fact that the melting endothermic peak in DSC curves was too small and diffuse to detect the decrease in $T_{\mathrm{m}, \mathrm{PE}}$. It is theoretically predicted ${ }^{42,43}$ that lamella thinning yields more space to accommodate the amorphous blocks (PCL blocks) to reduce the long period of the alternating structure consisting of PE lamellae and amorphous PCL + PE blocks. That is, lamella thinning may lead to the increase in the average distance of neighboring junction points between PCL and PE blocks, which yields the more relaxed conformation of amorphous PCL blocks to reduce the thickness of amorphous PCL layers. Therefore, total long period decreases discontinuously on the melting of PCL blocks, which originally arises from the gradual thinning of PE lamellae facilitated by further crystallization of PCL blocks at $T_{\mathrm{c}}$ for a long time.

Above speculation is solely based on the assumption that the decrease in PE crystallinity yields the thinning of PE lamellae existing in the system. Therefore, it is necessary to understand detailed changes in local morphology, in particular the change in PE and PCL crystals, during isothermal crystallization at $T_{\mathrm{c}}$.

\section{CONCLUSIONS}

We investigated the morphological evolution in a PCL- $b$-PE copolymer during isothermal crystallization over $3 \mathrm{~d}$ as a function of crystallization temperature $T_{\mathrm{c}}$ by SAXS, DSC, and FT/IR techniques. Following conclusions were obtained from this study.

1. The long period $L$ of crystallized morphology did not change at all during isothermal crystallization except the initial large increase in $L$ by the crystallization of PE and PCL blocks, indicating no macroscopic change in total morphology at the late stage crystallization.

2. The crystallinity of PCL blocks increased significantly and simultaneously that of PE blocks decreased moderately with increasing crystallization time $t_{\mathrm{c}}$ at the late stage crystallization, suggesting the partial melting of PE crystals facilitated by further crystallization of PCL blocks.

3. The PCL crystallinity increased significantly with increasing $T_{\mathrm{c}}$, and this increase exactly corresponded to the moderate decrease in PE crystallinity. This fact also suggests the crystallization-induced melting of PE crystals in our PCL- $b$-PE copolymer.

Acknowledgment. This work was supported in part by NEDO (New Energy and Industrial Technology Development Organization) launched in 2001 and also by Grants-in-Aid for Scientific Research on Basic Areas (B) (No. 17350102) from the Ministry of Education, Science, Sports, and Culture of Japan. The SR-SAXS measurement has been performed under the approval of Photon Factory Advisory Committee (No. 2006G078).

Received: April 14, 2008

Accepted: July 11, 2008

Published: August 28, 2008

\section{REFERENCES}

1. A. J. Müller, M. L. Arnal, and V. Balsamo, "Lecture Notes in Physics 714," G. Reiter and G. R. Strobl Ed., Springer, 2007.

2. S. Nojima, M. Ono, and T. Ashida, Polym. J., 24, 1271 (1992).

3. Z. Gan, J. Zhang, and B. Jiang, J. Appl. Polym. Sci., 63, 1793 (1997).

4. G. Floudas, G. Reiter, O. Lambert, and P. Dumas, Macromolecules, 31, 7279 (1998).

5. B. Bogdanov, A. Vidts, E. Schacht, and H. Berghmans, Macromolecules, 32, 726 (1999).

6. T. Shiomi, K. Imai, K. Takenaka, H. Takeshita, H. Hayashi, and Y. Tezuka, Polymer, 42, 3233 (2001).

7. J. Sun, X. Chen, C. He, and X. Jing, Macromolecules, 39, 3717 (2006).

8. C. He, J. Sun, T. Zhao, Z. Hong, X. Zhuang, X. Chen, and X. Jing, Biomacromolecules, 7, 252 (2006).

9. H. Takeshita, K. Fukumoto, T. Ohnishi, T. Ohkubo, M. Miya, K. Takenaka, and T. Shiomi, Polymer, 47, 8210 (2006).

10. L. Li, F. Meng, Z. Zhong, D. Byelov, W. H. Jeu, and J. Feijen, J. Chem. Phys., 126, 024904 (2007).

11. W. Yuan, J. Yuan, F. Zhang, X. Xie, and C. Pan, Macromolecules, 40, 9094 (2007).

12. J. Albuerne, L. Marquez, A. J. Müller, J. M. Raquez, P. Degee, P. Dubois, V. Castelletto, and I. W. Hamley, Macromolecules, 36, 1633 (2003).

13. A. J. Müller, J. Albuerne, L. Marquez, J. M. Ranques, P. Degee, P. Dubois, J. Hobbs, and I. W. Hamley, Faraday Discuss., 128, 231 (2004).

14. J. Albuerne, L. Marquez, A. J. Müller, J. M. Raquez, P. Degee, and P. Dubois, Macromol. Chem. Phys., 206, 903 (2005).

15. H. Schmalz, A. Knoll, A. J. Müller, and V. Abetz, Macromolecules, 35, 10004 (2002).

16. L. Sun, Y. Liu, L. Zhu, B. S. Hsiao, and C. A. Avila-Orta, Polymer, 45, 8181 (2004).

17. A. Boschetti-de-Fierro, L. Spindler, G. Reiter, D. Olmos, S Magonov, and V. Abetz, Macromolecules, 40, 5487 (2007). 
18. J. K. Kim, D. J. Park, M. S. Lee, and K. J. Ihn, Polymer, 42, 7429 (2001).

19. G. Maglio, A. Migliozzi, and R. Palumbo, Polymer, 44, 369 (2003).

20. R. M. Ho, P. Y. Hsieh, W. H. Tseng, C. C. Lin, B. H. Huang, and B. Lotz, Macromolecules, 36, 9085 (2003).

21. O. Jeon, S. H. Lee, S. H. Kim, Y. M. Lee, and Y. H. Kim, Macromolecules, 36, 5585 (2003).

22. I. W. Hamley, P. Parras, V. Castelletto, R. V. Castillo, A. J. Müller, E. Pollet, P. Dubois, and C. M. Martin, Macromol. Chem. Phys., 207, 941 (2006).

23. S. Nojima, Y. Akutsu, A. Washino, and S. Tanimoto, Polymer, 45, 7317 (2004).

24. S. Nojima, Y. Akutsu, M. Akaba, and S. Tanimoto, Polymer, 46, 4060 (2005).

25. S. Nojima, K. Ito, and H. Ikeda, Polymer, 48, 3607 (2007).

26. S. Nojima, T. Kiji, and Y. Ohguma, Macromolecules, 40, 7566 (2007).

27. H. Ikeda, Y. Ohguma, and S. Nojima, Polym. J., 40, 241 (2008).

28. S. Nojima, K. Kato, S. Yamamoto, and T. Ashida, Macromolecules, 25, 2237 (1992).

29. S. Nojima, H. Nakano, Y. Takahashi, and T. Ashida, Polymer, 35, 3479 (1994).

30. V. Crescenzi, G. Manzini, G. Calzolari, and C. Borri, Eur. Polym. J.,
8, 449 (1972).

31. "Polymer Handbook," 3rd ed., J. Brandrup and E. H. Immergut, Ed., Wiley, New York, 1989.

32. S. Nojima, H. Tsutsui, M. Urushihara, W. Kosaka, N. Kato, and T. Ashida, Polym. J., 18, 451 (1986).

33. S. Nojima, K. Kato, M. Ono, and T. Ashida, Macromolecules, 25, 1922 (1992).

34. M. Akaba and S. Nojima, Polym. J., 38, 559 (2006).

35. D. Verma, K. Katti, and D. Katti, J. Biomed. Mater. Res., 77A, 59 (2006).

36. H. Hagemann, R. G. Snyder, A. J. Peacock, and L. Mandelkern, Macromolecules, 22, 3600 (1989).

37. B. Wunderlich, "Macromolecular Physics vol. 2, Crystal Nucleation, Growth, Annealing,” Academic Press, New York, 1976.

38. H. Marand and Z. Huang, Macromolecules, 37, 6492 (2004).

39. Y. Chatani, Y. Okita, H. Tadokoro, and Y. Yamashita, Polym. J., 1 555 (1970).

40. P. R. Swan, J. Polym. Sci., 56, 409 (1962).

41. F. C. Stehling and L. Mandelkern, Macromolecules, 3, 242 (1970).

42. E. A. DiMarzio, C. M. Guttman, and J. D. Hoffman, Macromolecules, 13, 1194 (1980).

43. M. D. Whitmore and J. Noolandi, Macromolecules, 21, 1482 (1988). 